\title{
ANÁLISES DAS DESPESAS COM PESSOAL DAS CAPITAIS BRASILEIRAS NORDESTINAS
}

\author{
ANALYSIS OF PERSONNEL COSTS OF THE BRAZILIAN NORTHEASTERN CAPITAL CITIES
}

\author{
FÁBIA JAIANY VIANA DE SOUZA ${ }^{1}$ \\ MAURÍCIO CORRÊA DA SILVA² \\ RENATA PAES DE BARROS CÂMARA ${ }^{3}$
}

\begin{abstract}
RESUMO: O objetivo desta investigação é analisar a situação das despesas com pessoal das capitais nordestinas, no período de 2006 a 2016, em relação aos limites impostos pela Lei de Responsabilidade Fiscal (receita corrente líquida) e a receita corrente total. Como procedimentos metodológicos, o estudo utiliza a estratégia da pesquisa de avaliação de resultados com o método empírico-analítico (banco de dados). Os dados foram obtidos no sítio eletrônico da Secretaria do Tesouro Nacional (STN). Os resultados evidenciaram que os municípios de Aracaju (ano de 2006), Natal (2012) e São Luís (2012 e 2015) descumpriram o limite máximo de gasto na relação entre a Despesa Total com Pessoal (DTP) e a Receita Corrente Líquida (RCL) - gastos maiores que 54\%. Aracaju (2014), João Pessoa (2013 e 2015), Natal (2009, 2010, 2011, 2015 e 2016) e São Luís (2013, 2014 e 2016) ultrapassaram o limite prudencial (gastos maiores que 51,30\%). Aracaju (ano de 2016), João Pessoa (2012 a 2016), Maceió (2013, 2014 e 2016), Natal (2015 e 2016), São Luís (2010 e 2016) comprometeram mais de 55\% (inclusive) dos recursos das receitas correntes totais com as despesas com pessoal. Conclui-se que os gastos com pessoal representam um dos componentes principais dos itens de despesas públicas correntes e que deveriam ser analisados em relação a receita corrente total, pois esta é utilizada também para cobrir os gastos com juros e encargos da dívida e outras despesas correntes. A despesa total de pessoal, nos municípios analisados, aumentou mais que as receitas correntes líquidas.
\end{abstract}

Palavras-chave: Despesas Total com Pessoal. Receita Corrente Líquida. Pessoal e Encargos Sociais. Receita Corrente Total.

ABSTRACT: The purpose of this investigation is to analyze the status of personnel expenditure of the Brazilian northeastern capitals, in the period from 2006 to 2016, with respect to the limits imposed by the Tax Responsibility Law (net current revenue) and the total current revenue. With respect to methodological procedures, this study uses the strategy of outcomes assessment research with the empirical-analytical method (database). The data was obtained from the National Treasury Secretariat (STN) website. Results showed that the municipalities of Aracaju (in the year 2006), Natal (2012) and São Luís (2012 and 2015) did not comply with the maximum expenditure limit that is based on the relationship between the Total Personnel Expenditure (DTP) and the Net Current Revenue (RCL) -

Data de submissão: 17/05/2017 Data de aceite: 02/09/2018 Data de publicação: 18/09/2018

1 Mestre em Ciências Contábeis pelo Programa Multi-institucional e Inter-regional UnB/UFPB/UFRN (2014). Contadora do Instituto Federal de Educação,

Ciência e Tecnologia do Rio Grande do Norte - Campus Nova Cruz.

2 Doutor em Ciências Contábeis (Multi-institucional das UnB/UFPB/UFRN - 2014/2016). Professor Adjunto da Universidade Federal do Rio Grande do Norte

(UFRN) - Departamento de Ciências Contábeis, desde julho de 2009.

3 Doutora em Engenharia Mecânica pela Escola de Engenharia Mecânica de São Carlos - USP(2008). Atualmente é professora Adjunto I da Universidade Federal da Paraíba, ministrando aula na graduação e no programa Multi institucional de Pós Graduação da UnB - UFPB e UFRN. 
expenditures greater than 54\%. Aracaju (2014), João Pessoa (2013 and 2015), Natal (2009, 2010, 2011, 2015 and 2016) and São Luís (2013, 2014 and 2016) exceeded the prudential limit (expenditures higher than 51.30\%). Aracaju (2016), João Pessoa (2012 to 2016), Maceió (2013, 2014 and 2016), Natal (2015 and 2016), São Luís (2010 and 2016) spent more than $55 \%$ of total current revenues on personnel. It is concluded that personnel expenditures represent one of the main components of current public expenditure items and should be analyzed in relation to the total current revenue (RCT), because the RCT is also used to cover expenditure on interest and debt charges and other current expenses. Total personnel expenditure in the municipalities analyzed increased more than the net current revenues.

Keywords: Total Personnel Expenditure. Net Current Revenue. Personnel and Social Charges. Total Current Revenue.

\section{INTRODUÇÃO}

A Lei de Responsabilidade Fiscal - LRF (BRASIL, 2000) estabelece os limites de gastos com pessoal para as entidades públicas. A limitação ocorre por representar parcela significativa dos gastos do setor público nos orçamentos. No caso dos municípios, para o Poder Executivo, as Despesas Totais com Pessoal (DTP) não poderão ultrapassar $54 \%$ da Receita Corrente Líquida ( $R C L)$ e o limite prudencial (51,30\%) é considerado como alerta para tomar providências, tais como: aumentos e reajustes de remuneração, criação de cargos etc.

A Receita Corrente Líquida ( $R C L$ ) representa o somatório das Receitas Correntes (RC) deduzidos os valores determinados pela legislação (União: valores transferidos aos Estados e Municípios, etc., Estados: as parcelas entregues aos municípios e nos três a contribuição dos servidores para custeio de previdência e assistência social e as receitas de compensação financeira etc.). Os recursos denominados de Receitas Correntes (RC) - categoria econômica - representam as fontes para financiar as Despesas Correntes (DC) nos grupos de natureza: Pessoal e Encargos Sociais (PES); Juros e Encargos da Dívida (JED) e Outras Despesas Correntes (ODC) (BRASIL, 1964).

As RC são provenientes de impostos, taxas e contribuições e de transferências correntes recebidas (BRASIL, 1964). Outra categoria econômica de fontes de recursos são as Receitas de Capital (RCap), provenientes de operações de crédito, alienação de bens, amortização de empréstimos (recebidos) e transferências de capital que são destinadas para financiar os investimentos (INV), as inversões financeiras (INF) e amortização de dívidas (AMD). As INV, INF e AMD são os grupos de natureza das despesas de capital - DCap (BRASIL,1964).

Quando as Receitas Correntes (RC) superam as Despesas Correntes (DC), existirá o Superávit Corrente em que os recursos poderão ser capitalizados, ou seja, utilizados em Despesas de Capital (DCap). O Superávit Corrente, que são recursos gerados pelas entidades públicas com a cobrança de impostos, taxas e contribuições, representam as possibilidades de o setor público realizar benefícios para a sociedade em obras sem a necessidade de realizar empréstimos ou alienar bens, como ocorre com as Receitas de Capital (RCap).

As Despesas Correntes (DC) são aquelas que não contribuem, diretamente, para a formação ou aquisição de um bem de capital. São denominadas de despesas de custeio, ou seja, são utilizadas para a manutenção das atividades dos órgãos da administração pública, 
incluindo os gastos com pessoal e os destinados a atender a obras de conservação e adaptação de bens imóveis. Para Oliveira et al. (2013), a Despesa Total com Pessoal (DTP) de um município é uma despesa significativa dentro dos estudos econométricos sobre despesas e/ou investimentos públicos, uma vez que consome maior parte dos recursos públicos da maioria dos municípios brasileiros.

Do exposto, surge a questão de pesquisa: Qual a situação das despesas com pessoal das capitais nordestinas, no período de 2006 a 2016, em relação aos limites impostos pela Lei de Responsabilidade Fiscal (receita corrente líquida) e a receita corrente total? A resposta a essa questão permitirá aos munícipes e leitores conhecerem como os gestores municipais estão gerindo os gastos com pessoal. Observa-se, assim, que esta investigação tem o objetivo de analisar a situação das despesas com pessoal das capitais nordestinas, no período de 2006 a 2016, em relação aos limites impostos pela Lei de Responsabilidade Fiscal (receita corrente líquida) e a receita corrente total.

O estudo justifica-se pela relevância que a análise de resultados de ações governamentais tem para a sociedade, pois esta financia a gestão pública. Diariamente, os cidadãos cobram ações por melhoria nos serviços públicos de saúde, educação, transporte, saneamento etc. Dessa forma, torna-se necessário conhecer como os gestores da administração municipal estão cumprindo os limites previstos em lei, bem como, se estão utilizando os recursos correntes de forma equilibrada para atender os gastos correntes.

A sociedade tem o direito, tanto de conhecer a gestão pública, como participar dessa gestão com a institucionalização do controle social. Contudo, existe uma assimetria informacional, que com base na Teoria da Agência, pode ser analisada: os cidadãos desconhecem a gestão pública e são os titulares (principal) e os gestores públicos (os agentes) que conhecem essa gestão.

As análises poderão contribuir para a sociedade (os cidadãos) tomar ciência da gestão pública no quesito proposto, além de contribuir para a literatura com uma forma diferenciada de análises com métrica quantitativa das observadas em alguns estudos: Reis e Reis (2009); Araújo e Ribeiro (2013); Oliveira et al. (2013); Campagnoni, Platt Neto e Cruz (2014); Goulart et al. (2015) e Medeiros et al. (2017). Espera-se também, motivar outros pesquisadores a realizarem mais pesquisas de avaliação de resultados das entidades públicas.

Para atingir o objetivo proposto, esta investigação está amparada pela Teoria da Agência aplicada ao setor público, além de referencial teórico sobre desempenho e contas públicas e estudos anteriores. A Teoria da Agência trata de conflitos entre os agentes e o principal, como também da assimetria da informação. Os demais referenciais reforçam o estado da arte do conhecimento na área.

\section{REVISÃO DA LITERATURA}

\subsection{TEORIA DA AGÊNCIA APLICADA AO SETOR PÚBLICO}

A abordagem inicial da Teoria da Agência foi realizada por Jensen e Meckling (1976) na publicação de um artigo seminal. A teoria analisa os interesses entre os participantes relacionados a um meio organizacional ou sistema e verifica a ação de comportamento do principal (proprietário) e do outro (o agente). 
A Teoria da Agência (Principal-Agent), segundo Monsma (2000), trata das maneiras de conseguir serviços. O principal (pessoa ou organização) é quem necessita do serviço e o agente é a pessoa ou organização que executa o serviço. A teoria tenta identificar os incentivos que levam o agente a servir melhor os interesses do principal.

Mello (2006) demonstra a necessidade de elaborar métodos que minimizem a assimetria informacional existente entre agente e principal. Este fato pode ocasionar a decisão errada do agente (gestor público) para com o interesse do principal (cidadão).

O problema da agência decorre dos interesses divergentes entre o principal e o agente e da existência da assimetria da informação, em razão do problema de surgir no momento em que as informações disponíveis são desiguais entre os participantes (ARROW, 1984; LERUTH; PAUL, 2006).

Observa-se que a Teoria da Agência, embora tenha sido utilizada para analisar os conflitos no meio empresarial, pode ser aplicada no setor público, haja vista a similaridade relacionada com os interesses e a assimetria informacional. Os gestores públicos conhecem os atos e fatos relacionados com a gestão pública e a população, de modo geral, desconhecem. As análises das gestões públicas pelos acadêmicos podem diminuir a assimetria informacional com a realização e divulgação de pesquisas sociais.

Neste sentido, Secchi (2013) afirma que a Teoria da Agência (modelo principalagente) pode ser usada para interpretar fenômenos em políticas governamentais. Suzart (2012), embasado na Teoria da Agência, afirma que há evidências de que os gestores públicos, ao invés de atender aos anseios sociais, podem buscar saciar interesses pessoais.

Segundo Malmir et al. (2014), a Teoria da Agência pode ter o efeito de criar uma nova administração pública por destacar questões em relação às responsabilidades das estruturas estatais que distingue das estruturas privadas. Esta teoria faz com que os agentes atuem e sejam responsáveis perante os interesses de seus cidadãos.

Neste prisma, para Dawson et al. (2016), a Teoria da Agência pode ser aplicada ao setor público, embora seja necessário um entendimento-chave dos atores envolvidos. Ao entender que a governança não precisa ser um jogo de soma zero em que o principal ganha e o agente perde ou vice-versa, uma mudança intelectual pode ser feita para maximizar os resultados positivos em vez de simplesmente tentar evitar resultados negativos. Dado o tamanho e a amplitude dos serviços oferecidos pelo Estado e a crítica dos serviços pelos cidadãos, tal mudança poderia ter impactos profundos sobre a qualidade das vidas daqueles a quem os governos servem.

Rocha et al. (2012) argumentam que a contabilidade pode auxiliar a reduzir a assimetria da informação, no momento em que são divulgadas as demonstrações financeiras atualizadas da organização, observado que os investidores não possuem mesmo nível de acesso as informações que os administradores da entidade.

Observa-se na perspectiva de Mello (2006); Suzart (2012); Secchi (2013); Malmir et al. (2014) e Dawson et al. (2016) que as análises dos gastos públicos e o desempenho das entidades públicas podem ser inseridas no contexto do arcabouço fundamentado pela Teoria da Agência (esclarecimentos para o cidadão sobre a gestão pública).

As pesquisas avaliativas de resultados de ações governamentais podem diminuir a assimetria informacional ao serem evidenciadas a forma como os recursos públicos foram utilizados. Desse modo, os gestores públicos poderão ter uma nova visão para o monitoramento e a avaliação das políticas públicas implementadas e os cidadãos terão condições de conhecer o desempenho de seus gestores. 


\subsection{DESEMPENHO E CONTAS PÚBLICAS}

A avaliação de desempenho pode contribuir para a reversão da falta de canais que possibilitem acesso aos cidadãos para que possam reivindicar e saber o que realmente ocorre na administração pública, através de uma avaliação formal e objetiva clara e útil (TEIXEIRA; SANTANA, 1994).

A avaliação de desempenho consiste num exame regular e cuidadoso da implementação das políticas públicas e análise dos resultados alcançados (JULNES, 2006). Para Machado, Machado e Holanda (2007), a avaliação de desempenho tem como finalidade servir como ferramenta para uma gestão eficaz. Para isso, deve-se observar alguns aspectos, como bases informativas, variáveis consideradas, critérios, conceitos e princípios adotados.

A palavra desempenho é um termo sujeito a inúmeras variações semânticas e conceituais. O desempenho ou performance de um indivíduo, de uma organização, de um grupo etc., que se pretende avaliar, pode ser expresso com a utilização de uma métrica, função ou índice de desempenho em relação às metas, requisitos ou expectativas previamente definidas (SILVA et al., 2016).

Os dados para que sejam avaliados os desempenhos das entidades públicas constam nos demonstrativos estabelecidos na Lei no 4.320, de 17 de março de 1964 (BRASIL, 1964) e na Lei Complementar no 101, de 04 de maio de 2000 - LRF (BRASIL, 2000). A Lei 4.320/1964 (BRASIL, 1964) estabelece, inclusive, que os serviços de contabilidade serão organizados de forma a permitirem o acompanhamento da execução orçamentária, o conhecimento da composição patrimonial, a determinação dos custos dos serviços industriais, o levantamento dos balanços gerais, a análise e a interpretação dos resultados econômicos e financeiros.

A avaliação de desempenho das entidades públicas pode servir para o gestor público verificar se os objetivos das ações de políticas públicas estão sendo alcançados ou não. Para a sociedade, a avaliação pode servir como forma de conhecer a gestão e como os gestores públicos estão utilizando os recursos que foram por ela disponibilizados.

Para avaliar o desempenho é necessário analisar os demonstrativos públicos e conhecer a respectiva legislação. Observa-se assim, que além de instituir os demonstrativos para serem evidenciadas as contas públicas, a Lei 4.320/1964 (BRASIL, 1964) e a LRF (BRASIL, 2000) e outros mandamentos legislativos, como a Portaria $n=42$, de 14 de abril de 1999, do Ministério do Planejamento, Orçamento e Gestão - MPOG (BRASIL, 1999) e Portaria Interministerial no 163, de 04 de maio de 2001 da Secretaria do Tesouro Nacional - STN e da Secretaria de Orçamento Federal - SOF (BRASIL, 2001) estruturam e disciplina a gestão pública.

Quanto ao desempenho e as ações relacionadas com os gastos de pessoal, principal objetivo desta investigação, existem estudos que realizaram as avaliações. Para Goulart et al. (2015), a limitação do gasto com pessoal é um dos mecanismos utilizados pela LRF para estabelecer responsabilidades aos gestores públicos na gerência das contas públicas. A repartição dos limites globais nos Poderes Executivo, Legislativo, Judiciário e Ministério Público, foram necessários para enfrentar o problema do descontrole das despesas com pessoal em todos os entes da Federação.

De acordo com Oliveira et al. (2013), a sociedade deve ter em mente que a despesa com pessoal faz parte de um conjunto de despesas, ao lado da dívida e de outros indicadores da gestão financeira, que são periodicamente avaliadas, sobretudo porque a lei fiscal impõe a obediência a limites de austeridade, como parte significante do pacto federativo. Assim, deve-se compreender que o item despesa com pessoal é parte de um 
todo mais complexo do sistema financeiro público, e que o não cumprimento resulta por fragmentar o pacto federativo.

Campagnoni, Platt Neto e Cruz (2014) esclarecem que a LRF reforça o controle sobre os gestores, de modo que o equilíbrio orçamentário seja mantido, para que todas as despesas necessárias na administração pública sejam contempladas. As despesas com pessoal são significativas no setor público.

Observa-se que os estudos de Oliveira et al. (2013), Campagnoni, Platt Neto e Cruz (2014) e Goulart et al. (2015) reforçam a preocupação que o gestor público deve ter para o manter o equilíbrio das contas públicas. Os gastos com pessoal representam um dos itens que compõem as contas públicas. No caso das despesas correntes, são incluídas também os gastos com juros e encargos da dívida e as outras despesas correntes (despesas com energia, telefone, manutenção das instalações etc.)

Uma das maneiras de entender as diversas áreas de despesas (correntes e de capital) que competem ao setor público e assim observar as áreas contempladas pela administração pública são as funções de governo estabelecidas na Lei 4.320/64 (BRASIL, 1964) e atualizadas pela Portaria no 42, de 14 de abril de 1999, do Ministério do Planejamento, Orçamento e Gestão - MPOG (BRASIL, 1999). São estabelecidas 28 funções de governo, como: legislativa, judiciária, administração, segurança pública, educação, saúde, saneamento etc. Desse modo, pode-se verificar que as fontes de recursos (receitas correntes e receitas de capital) devem contemplar muitas áreas de competência das entidades públicas.

Os gastos com pessoal não representam a atividade-fim das instituições públicas. São meios de cumprir com suas finalidades (atividades-meio). As entidades públicas devem oferecer serviços ou proporcionar atividades para atender as necessidades coletivas em assistência médica e hospitalar, jurídica, tratamento de esgoto e lixo, abastecimento de água, dentre outros.

\subsection{ESTUDOS ANTERIORES}

São encontrados diversos estudos que tratam das análises das despesas com pessoal, tanto na área federal, estadual e municipal. A seguir alguns relatos.

Reis e Reis (2009) avaliaram a situação fiscal do estado de Rondônia antes e depois da promulgação (1999-2007) da Lei de Responsabilidade Fiscal com o objetivo de verificarem o comportamento das despesas com pessoal. O estado de Rondônia por muito tempo esteve em desequilíbrio financeiro, chegando a ter $85 \%$ da sua RCL comprometida com despesas de pessoal. Contudo, entre 1999 e 2001 uma série de medidas de natureza fiscal foi tomada em busca do reequilíbrio orçamentário e os resultados foram surpreendentes: o aumento de receitas próprias foi significativo; houve redução de despesas com pessoal em relação à $\mathrm{RCL}$ e aumento do superávit primário. Mesmo com aumento dos gastos com pessoal - motivado por aumento dos salários, contratação de novos servidores, entre outros, o estado de Rondônia tem mantido em níveis satisfatórios, até mesmo abaixo do limite prudencial, suas despesas com pessoal.

Araújo e Ribeiro (2013) analisaram a situação das despesas com pessoal dos municípios da Região VIII do Zoneamento Sócio Econômico Ecológico (ZSEE), do Estado do Mato Grosso (MT) entre os anos de 2007 a 2010. Verificaram que Tangará da Serra não observou o limite prudencial no ano de 2009 e que os seus gastos foram acima da média da região. Observaram que o comprometimento médio da $\mathrm{RCL}$ da região evoluiu 6,89 pontos percentuais de 2007 para 2010. O município de Denise evoluiu 11,50 pontos percentuais e 
Tangará da Serra 7,12. Analisando a evolução da despesa total com pessoal de Denise nos anos de 2007 a 2010 o aumento foi de $89,18 \%$, enquanto a RCL foi de apenas $46,18 \%$, no entanto, Tangará da Serra evoluiu $63,17 \%$ e $43,80 \%$, respectivamente.

Oliveira et al. (2013) analisaram os gastos com pessoal dos municípios da região metropolitana de Natal, no período de 2003 a 2010. Os resultados do estudo apontaram, de forma conclusiva, que os municípios da Região Metropolitana de Natal estão buscando atingir o limite legal da Despesa Total com Pessoal. Entretanto, os gestores estão usando como balizador de decisão, não necessidades e especificidades municipais de atendimento aos cidadãos, mas um critério ancorado no aumento da receita municipal. Desprezam o vínculo com demanda populacional e/ou a infraestrutura municipal, ocasionando assim anomalias fiscais, podendo ser entendido até como uma afronta ao pacto federativo, em que pequenos municípios, com pequenas populações, infraestrutura limitada e elevada arrecadação empregam o limite superior de $54 \%$ para a DTP, estabelecidos na Lei de Responsabilidade Fiscal.

Campagnoni, Platt Neto e Cruz (2014) evidenciaram a observância do cumprimento dos limites para despesas com pessoal, estabelecidos na Lei de Responsabilidade Fiscal, pelos Poderes e órgãos da União, no período de 2000 a 2013. Constataram que os Poderes e os órgãos da União cumpriram os limites máximo, prudencial e de alerta, em todos os anos analisados. Procedeu-se a um ajuste monetário com vistas a verificar a evolução da Despesa Total com Pessoal (DTP) e da Receita Corrente Líquida (RCL). Entre 2000 e 2013, a RCL apresentou uma variação de $99,45 \%$. A DTP, por sua vez, cresceu $42,74 \%$.

Goulart et al. (2015) analisaram o controle das despesas com pessoal dos municípios que compõem o Consórcio da Quarta Colônia de Desenvolvimento Sustentável - CONDESUS (Agudo, Dona Francisca, Faxinal do Soturno, Ivorá, Nova Palma, Pinhal Grande, Restinga Seca, São João do Polêsine e Silveira Martins), durante os anos de 2002 a 2012. De forma geral, pelos resultados da pesquisa, todos os municípios cumpriram as determinações impostas. Contudo, sugerem que outros critérios sejam empregados para avaliar esses entes, principalmente levando em consideração as dificuldades locais, contribuindo, dessa forma, para um melhor planejamento estratégico municipal e para elaboração e efetivação de políticas públicas eficazes.

Medeiros et al. (2017) analisaram a tendência linear dos indicadores de despesas com pessoal e a correlação deste com o perfil de gastos com pessoal da saúde de 5.356 municípios brasileiros, entre 2004 e 2009. Observaram uma tendência de aumento de 1,3\% nas médias anuais da despesa total com pessoal dos municípios, porém, as despesas com pessoal da saúde não acompanharam esse crescimento. Não houve correlação entre os indicadores, portanto, esse resultado se opõe aos argumentos dos gestores de saúde, que atribuem à LRF os problemas para contratação de trabalhadores e expansão dos sistemas de saúde.

Observa-se que os estudos de Reis e Reis (2009), Araújo e Ribeiro (2013), Oliveira et al. (2013), Campagnoni, Platt Neto e Cruz (2014) e de Goulart et al. (2015) analisaram os gastos com pessoal em relação a receita corrente líquida (limite legal) e esta investigação, além de realizar essas análises, apresenta as relações de gastos com pessoal (grupo de natureza das despesas da categoria econômica das despesas correntes) com a receita corrente total. Isto significa um diferencial de análise acrescentado. $O$ estudo de Medeiros et al. (2017), além de analisar os gastos com pessoal faz uma correlação com os gastos com pessoal na saúde. A relevância desses estudos ao demonstrar para a população como os 
gestores públicos estão gerindo os gastos com pessoal está na diminuição da assimetria informacional existente entre a sociedade (principal) e os gestores públicos (agentes).

\section{PROCEDIMENTOS METODOLÓGICOS}

\subsection{CARACTERIZAÇÃO DA PESQUISA, DO MÉTODO E DA BASE DE DADOS}

Esta investigação utiliza a estratégia da pesquisa de avaliação de resultados. Para Martins e Theóphilo (2009), essa é uma estratégia empírica aplicada para avaliar programas, projetos, políticas etc.

O método de pesquisa utilizado é o empírico-analítico (arquivo/empirista - banco de dados) que corresponde à utilização de técnica de coleta, tratamento e análise de dados com métricas quantitativas. Matias-Pereira (2012) esclarece que nesse método, o processo de validação da prova científica é feito por meio de testes dos instrumentos, graus de significância e sistematização das definições operacionais.

A utilização do empirismo, conforme afirmam Bastos e Keller (2004), colocam a mensuração quantitativa como critério do que seria ou não científico. 0 empirismo, para os autores, busca reproduzir as condições do fenômeno em laboratório, com a pretensão de reconstruir o ambiente propício capaz de superar subjetivismos, incursões de juízos de valor e influências ideológicas.

A população, desta investigação, abrange todos os 5.570 (cinco mil, quinhentos e setenta) municípios brasileiros, conforme o Instituto Brasileiro de Geografia e Estatística (IBGE) do ano de 2016 (BRASIL, 2017). A amostra é constituída de 09 (nove) municípios que são as capitais dos Estados da Região Nordeste Brasileira (Tabela 2). Foi utilizada a técnica de amostragem não probabilística por conveniência (a cargo do pesquisador), haja vista que não se pode generalizar os resultados das análises de gastos com pessoal (as inferências são realizadas caso a caso) e é necessário delimitar os dados na pesquisa científica. Por outro, pode-se justificar a escolha também, pela representatividade em relação a quantidade de capitais estaduais brasileiras (análises de $34,62 \%$ da população - 26 capitais).

O aspecto temporal de análises das variáveis do Quadro 1 foram os anos de 2006 a 2016. Não foram incluídos outros anos por falta de dados no ano de 2005 (períodos anteriores) e o ano de 2017 ainda não estava com os seus dados anuais completos. As variáveis escolhidas constam no Quadro 1.

Quadro 1 - Variáveis escolhidas e suas relações

\begin{tabular}{|l|c|l|}
\hline \multicolumn{1}{|c|}{ Variáveis } & Relações entre as variáveis & \multicolumn{1}{|c|}{ Resultados } \\
\hline Despesas Total com Pessoal (DTP) & DTP / RCL & $\begin{array}{l}\text { Limite de gasto e limite } \\
\text { prudencial. }\end{array}$ \\
\hline Receita Corrente Líquida (RCL) & PES / RC & $\begin{array}{l}\text { Peso dos gastos em relação } \\
\text { aos recursos correntes. }\end{array}$ \\
\hline Despesas de Pessoal e Encargos Sociais (PES) & Receita Corrente (RC). & PES
\end{tabular}

Fonte: dados da pesquisa.

Os dados foram extraídos do Anexo 1 (Balanço Orçamentário) do Relatório Resumido da Execução Orçamentária (RREO) do 60 Bimestre (novembro/dezembro) e do Anexo 1 (Demonstrativo da Despesa com Pessoal) do Relatório de Gestão Fiscal (RGF) do 3응 Quadrimestre (setembro a dezembro) disponibilizados no sítio eletrônico da Secretaria do Tesouro Nacional - STN (BRASIL, 2018). 
Os dados foram atualizados para o dia 31 de dezembro de 2017 pela variação do IGPDI (Índice Geral de Preços-Disponibilidade Interna) da Fundação Getúlio Vargas (FGV). O IGPDI é utilizado pela Secretaria do Tesouro Nacional (STN) para atualizar os valores de séries históricas de receitas e despesas. A Tabela 1 apresenta os fatores de correção (atualização).

\section{Tabela 1 - Fatores de correção (atualização) pelo IGP-DI}

\begin{tabular}{lr}
\hline \multicolumn{1}{c}{ Período } & Fator de correção (atualização) \\
\hline 31.12.2016 para 31.12.2017: & 0,996659 \\
31.12.2015 para 31.12.2017: & 1,063822 \\
31.12.2014 para 31.12.2017: & 1,176720 \\
31.12.2013 para 31.12.2017: & 1,224972 \\
31.12.2012 para 31.12.2017: & 1,292300 \\
31.12.2011 para 31.12.2017: & 1,385751 \\
31.12.2010 para 31.12.2017: & 1,463083 \\
31.12.2009 para 31.12.2017: & 1,620547 \\
31.12.2008 para 31.12.2017: & 1,591992 \\
31.12.2007 para 31.12.2017: & 1,770303 \\
31.12.2006 para 31.12.2017: & 1,887351 \\
\hline
\end{tabular}

Fonte: adaptado de Cálculo Exato (2018).

Os fatores de correção (atualização) da Tabela 1 têm a finalidade de posicionar os dados em mesma base (31.12.2017) para as comparações de resultados na análise de regressão.

\subsection{TÉCNICA DE ANÁLISE E INTERPRETAÇÃO DOS DADOS}

A técnica utilizada na análise e interpretação dos dados escolhida foi a regressão linear simples (MQO - Mínimos Quadrados Ordinários). A análise de regressão fornece uma função matemática que descreve a relação entre duas ou mais variáveis (BRUNI, 2009). Segundo Lattin, Carroll e Green (2011), a análise de regressão é usada para responder os seguintes tipos de questões: descrição (como descrever a relação entre as variáveis); inferência (a relação descrita é estatisticamente significativa) e a previsão (o modelo generaliza bem as observações fora da amostra).

Para se estimar o valor esperado, usa-se de uma equação, que determina a relação entre ambas as variáveis.

$Y_{1}=\alpha+\beta X_{1}+\varepsilon$

Em que: $Y_{1}$ - Variável explicada (dependente); é o valor que se quer atingir;

$\alpha$ - É uma constante, que representa a interceptação da reta com o eixo vertical (intercepto);

$\beta$ - É outra constante, que representa o declive (coeficiente angular) da reta (coeficiente da regressão);

$X_{1}$ - Variável explicativa (independente), representa o fator explicativo na equação;

$\varepsilon$ - Variável que inclui todos os fatores residuais mais os possíveis erros de medição. O seu comportamento é aleatório, devido à natureza dos fatores que encerra. 
Para que essa equação possa ser aplicada, a variável dependente e os resíduos estimados devem ter distribuição normal; não pode haver correlação elevada entre os resíduos e a variável explicativa de ter resíduos homocedásticos e não pode ter multicolinearidade (FÁVERO, 2015).

Os testes realizados para dar validade e confiabilidade aos resultados desta investigação foram os seguintes: as variáveis dependentes e os resíduos estimados apresentaram distribuição normal com o Teste de Shapiro-Francia; os resíduos foram considerados homocedásticos no Teste de Breusch-Pagan e a multicolinearidade apresentou valores compatíveis (inferiores a 5 ). Os $p$-valores do Teste $F$ que na regressão linear simples são os mesmos para os Teste $t$ apresentaram significância estatística (valores inferiores a $0,05)$ em todas as equações. A qualidade do ajuste do modelo explicada pelos dados coletados com o $\mathrm{R}^{2}$ Ajustado (coeficiente de determinação ajustado) ficou na faixa de $63,66 \%(0,6366)$ a $99,01 \%(0,9901)$. Observa-se assim, que os testes dos pressupostos para utilizar a regressão linear simples foram atendidos.

\section{RESULTADOS E DISCUSSÕES}

A Tabela 2 apresenta os resultados dos recursos aplicados pelas capitais nordestinas, no período de 2006 a 2016, em relação aos gastos de Despesas Total de Pessoal (DTP) e a Receita Corrente Líquida (RCL), os quais servem para analisar o cumprimento do limite máximo de gastos (54\%) e do limite prudencial (51,30\%). Apresenta também, a aplicação dos recursos das despesas com Pessoal e Encargos Sociais (PES) - grupo de natureza das despesas da categoria econômica Despesas Correntes (DC) - com a Receita Corrente Total $(\mathrm{RC})$.

Observa-se na Tabela 2, que os municípios de Aracaju (ano de 2006), Natal (2012) e São Luís (2012 e 2015) descumpriram o limite máximo de gasto na relação DTP e RCL (gastos maiores que 54\%). Aracaju (2014), João Pessoa (2013 e 2015), Natal (2009, 2010, 2011, 2015 e 2016) e São Luís $(2013,2014$ e 2016) ultrapassaram o limite prudencial (gastos maiores que 51,30\%). Desse modo, descumpriram o inciso III, Art. 20 da LRF (BRASIL, 2000) para o caso do limite máximo de gastos de despesas total de pessoal e não observaram o parágrafo único do Art. 22 da LRF (BRASIL, 2000) para o limite prudencial. Estes achados diferem dos apresentados na pesquisa de Oliveira et al. (2013) para os municípios da Região Metropolitana de Natal e de Goulart et al. (2015) para os municípios que compõem o Consórcio da Quarta Colônia. Os autores verificaram cumprimento das determinações impostas pela LRF.

$A$ relação $P E S$ e $R C$, embora não apresente uma determinação legal, serve para analisar o comprometimento dos recursos arrecadados correntes (RC) em relação aos gastos com o grupo de natureza das despesas correntes denominado de PES, em detrimento aos demais grupos de natureza dessas despesas (Juros e Encargos da Dívida - JED e Outras Despesas Correntes - ODC). Assim, observa-se na Tabela 2, que Aracaju (ano de 2016), João Pessoa (2012 a 2016), Maceió (2013, 2014 e 2016), Natal (2015 e 2016), São Luís (2010 e 2016) comprometeram mais de $55 \%$ (inclusive) dos recursos das receitas correntes (RC) em apenas um grupo de natureza de despesa (PES). 
Tabela 2 - Aplicações percentuais de recursos da DTP em relação a RCL e de PES com a RC das Capitais Nordestinas (2006 a 2016)

\begin{tabular}{|c|c|c|c|c|c|c|}
\hline \multirow{2}{*}{$\begin{array}{c}\text { ANO } \\
\text { DEZEMBRO }\end{array}$} & \multicolumn{2}{|c|}{ ARACAJU-SE } & \multicolumn{2}{|c|}{ FORTALEZA-CE } & \multicolumn{2}{|c|}{ JOÃO PESSOA-PB } \\
\hline & DTP/RCL & PES/RC & DTP/RCL & PES/RC & DTP/RCL & PES/RC \\
\hline 2016 & 49,40 & 55,79 & 46,89 & 51,55 & 49,34 & 55,00 \\
\hline 2015 & 50,89 & 54,03 & 44,79 & 48,36 & $53,44 * *$ & 59,03 \\
\hline 2014 & $51,65 * *$ & 50,93 & 47,04 & 49,83 & 50,40 & 58,37 \\
\hline 2013 & 50,43 & 50,28 & 50,95 & 52,72 & $52,54 * *$ & 57,91 \\
\hline 2012 & 47,19 & 46,81 & 43,67 & 45,55 & 50,61 & 55,38 \\
\hline 2011 & 45,65 & 45,68 & 42,09 & 44,21 & 38,74 & 46,32 \\
\hline 2010 & 49,49 & 48,83 & 43,14 & 44,65 & 42,85 & 46,16 \\
\hline 2009 & 47,37 & 47,36 & 45,32 & 46,75 & 34,47 & 42,14 \\
\hline 2008 & 47,49 & 46,84 & 42,14 & 45,22 & 37,27 & 44,34 \\
\hline 2007 & 50,30 & 49,93 & 42,34 & 47,97 & 34,60 & 42,40 \\
\hline 2006 & $54,25 *$ & 51,17 & 40,12 & 49,15 & 44,32 & 46,06 \\
\hline Média = & 49,46 & 49,79 & 44,41 & 47,82 & 44,42 & 50,28 \\
\hline ANO & \multicolumn{2}{|c|}{ MACEIÓ-AL } & \multicolumn{2}{|c|}{ NATAL - RN } & \multicolumn{2}{|c|}{ RECIFE - PE } \\
\hline DEZEMBRO & DTP/RCL & PES/RC & DTP/RCL & PES/RC & DTP/RCL & PES/RC \\
\hline 2016 & 49,40 & 55,79 & $53,13 * *$ & 55,06 & 49,98 & 52,77 \\
\hline 2015 & 50,89 & 54,03 & $53,50 * *$ & 56,09 & 49,74 & 53,22 \\
\hline 2014 & 51,15 & 56,28 & 48,94 & 48,13 & 44,67 & 46,28 \\
\hline 2013 & 50,88 & 55,51 & 48,71 & 46,39 & 45,97 & 47,15 \\
\hline 2012 & 47,90 & 52,35 & $54,56^{*}$ & 53,39 & 42,88 & 41,60 \\
\hline 2011 & 42,29 & 46,93 & $53,59 * *$ & 53,75 & 42,43 & 41,89 \\
\hline 2010 & 45,93 & 41,65 & $51,58 * *$ & 51,49 & 46,32 & 45,63 \\
\hline 2009 & 47,61 & 39,46 & $51,78 * *$ & 50,97 & 41,80 & 42,01 \\
\hline 2008 & 38,80 & 35,80 & 41,71 & 41,22 & 41,92 & 42,51 \\
\hline 2007 & 37,34 & 35,10 & 45,74 & 45,65 & 40,37 & 41,33 \\
\hline 2006 & 40,44 & 44,56 & 44,90 & 45,78 & 38,97 & 39,38 \\
\hline Média = & 45,69 & 47,04 & 49,83 & 49,81 & 44,10 & 44,89 \\
\hline ANO & \multicolumn{2}{|c|}{ SALVADOR-BA } & \multicolumn{2}{|c|}{ SÃO LUÍS - MA } & \multicolumn{2}{|c|}{ TERESINA - PI } \\
\hline DEZEMBRO & DTP/RCL & PES/RC & DTP/RCL & PES/RC & DTP/RCL & PES/RC \\
\hline 2016 & 42,05 & 42,70 & $53,27 * *$ & 56,53 & 48,54 & 52,62 \\
\hline 2015 & 43,90 & 42,99 & $55,18^{*}$ & 47,47 & 49,70 & 51,90 \\
\hline 2014 & 41,34 & 41,13 & $52,87 * *$ & 46,53 & 48,38 & 51,78 \\
\hline 2013 & 46,70 & 43,75 & $51,77 * *$ & 45,17 & 49,65 & 50,40 \\
\hline 2012 & 44,50 & 41,60 & $54,36^{*}$ & 44,31 & 48,38 & 49,31 \\
\hline 2011 & 38,29 & 36,52 & 50,99 & 44,92 & 46,60 & 44,99 \\
\hline 2010 & 41,59 & 37,74 & 50,93 & 59,39 & 46,04 & 41,56 \\
\hline 2009 & 33,72 & 36,75 & 43,99 & 46,48 & 42,73 & 39,77 \\
\hline 2008 & 29,61 & 32,94 & 43,66 & 39,89 & 42,65 & 39,72 \\
\hline 2007 & 28,63 & 31,83 & 43,02 & 39,55 & 36,93 & 41,47 \\
\hline 2006 & 31,42 & 34,28 & 42,01 & 36,82 & 38,01 & 37,63 \\
\hline Média = & 38,34 & 38,38 & 49,28 & 46,10 & 45,24 & 45,56 \\
\hline
\end{tabular}

Legenda: $\left({ }^{*}\right)$ = máximo de 54\%; $\left({ }^{* *}\right)=$ limite prudencial de 51,30\%; ano/dezembro = valores anuais apurados em dezembro.

Fonte: dados da pesquisa.

Na relação PES e RC, o excesso de recursos aplicados significa uma diminuição de recursos para o pagamento de juros e encargos de dívida - JED (despesas orçamentárias com o pagamento de juros, comissões e outros encargos de operações de crédito internas e externas contratadas, bem como da dívida pública mobiliária) e outras despesas correntes ODC (despesas orçamentárias com aquisição de material de consumo, pagamento de diárias, contribuições, subvenções, auxílio-alimentação, auxílio-transporte, além de outras despesas 
da categoria econômica "Despesas Correntes" não classificáveis nos demais grupos de natureza de despesa). Observa-se que a análise de PES e RC, além de evidenciar preocupações com a utilização das receitas correntes e os grupos de natureza que compõem as despesas correntes, pode ser utilizada como outro critério para avaliar a gestão pública municipal conforme sugerido por Goulart et al. (2015).

A média da média da relação DTP/RCL para todos os municípios, no período de 2006 a 2016 , foi de $45,64 \%$ e entre PES/RC foi de $45,63 \%$. Embora, os valores sejam muito próximos, observa-se que Aracaju diminuiu os gastos da DTP para atender as exigências legais de 2006 (ano base) para 2016 (diminuição de 8,94\%). A maioria aumentou os gastos de 2006 (ano base) para 2016: Fortaleza (aumentou 16,87\%); João Pessoa (11,32\%); Maceió (22,25\%); Natal (18,32\%); Recife (28,25\%); Salvador (33,83\%); São Luís (26,80\%) e Teresina $(27,70 \%)$. O estudo de Reis e Reis (2009), embora aborde a área estadual, corrobora em parte com esta investigação quando a entidade pública toma ciência do comportamento das despesas com pessoal e toma as providências correlatas (Aracaju diminuiu os gastos).

O descumprimento de determinação legal sobre os limites de gastos com pessoal significa desequilíbrio das contas públicas. No caso, a administração pública não poderá reajustar as remunerações dos servidores públicos, criar novos cargos, realizar novas admissões ou contratações de pessoal etc. A relação de gastos com pessoal, juros e encargos da dívida e outras despesas correntes e a receita corrente total significa a alocação de recursos para manter a entidade pública em funcionamento.

Os achados desta investigação e de correlatas (REIS; REIS, 2009; ARAÚJO; RIBEIRO, 2013; OLIVEIRA et al., 2013; CAMPAGNONI; PLATT NETO; CRUZ, 2014; GOULART et al., 2015 e MEDEIROS et al., 2017) são consideradas estratégias de pesquisas de avaliação de resultados de gestão pública ao empregar métricas quantitativas.

Neste prisma, observa-se que os resultados desta investigação e das pesquisas correlatas representam para a sociedade uma forma de conhecer a gestão dos gastos com pessoal em relação aos limites legais e a estrutura relacionada com os grupos de natureza das despesas correntes. Conforme preceitua a Teoria da Agência (SUZART, 2012; SECCHI, 2013; MALMIR et al., 2014) sobre a assimetria informacional, pode-se afirmar, com base nos achados desta investigação, que os leitores e os munícipes, agora, podem conhecer com os gestores municipais das capitais nordestinas administraram os gastos com pessoal, no período de 2006 a 2016.

A Tabela 3 apresenta os resultados de 18 equações de regressão linear simples que são utilizadas para analisar a relação (associação) entre as variáveis escolhidas. As análises representam outra forma de avaliar os gastos com pessoal.

Observa-se nas equações ímpares (variável dependente DTP) que os coeficientes angulares estiveram na faixa de 0,5018 (Eq. 1) no município de Aracaju a 0,7747 (Eq. 15) em São Luís. Isto indicou, no período de 2006 a 2016, que um aumento de $\mathrm{R} \$ 1,00$ na $\mathrm{RCL}$ provocou, em média, um aumento (autorização para gastar) de cerca de $\mathrm{R} \$ \mathbf{0 , 5 0}$ a $\mathrm{R} \$ 0,77$, respectivamente, nas despesas total de pessoal (DTP). Ou seja, as despesas médias de pessoal aumentaram cerca de $\mathrm{R} \$ 0,50$ a $\mathrm{R} \$ 0,77$ a cada aumento de $\mathrm{R} \$ 1,00$ na RCL. Estes resultados para o munícipio de São Luís são convalidados com os da Tabela 2, que descumpriu o limite de gasto de despesas total de pessoal em relação a receita corrente líquida de 54\% nos anos de 2012 e 2015 e ultrapassou o limite prudencial nos anos de 2013, 2014 e 2016. 
Tabela 3 - Análise de Regressão por MQO das relações entre as DTP e a RCL e de PES com RC das Capitais Nordestinas (2006 a 2016)

\begin{tabular}{|c|c|c|c|}
\hline \multicolumn{4}{|c|}{ ARACAJU - SE } \\
\hline Variável dependente: DTP & Teste F & P-valor & $\mathrm{R}^{2}$ Ajustado \\
\hline$Y_{D T P}=-9834631+0,501808731 R C L$ (Eq. 1) & 248,1889 & $0,00000 *$ & 0,9611 \\
\hline Variável dependente: PES & & & \\
\hline$Y_{P E S}=-131560737+0,59844417 R C$ (Eq. 2) & 232,0618 & $0,00000^{*}$ & 0,9585 \\
\hline \multicolumn{4}{|c|}{ FORTALEZA -CE } \\
\hline Variável dependente: DTP & Teste F & P-valor & $\mathrm{R}^{2}$ Ajustado \\
\hline$Y_{D T P}=-453992434+0,543837445 R C L$ (Eq. 3) & 87,2968 & $0,00000^{*}$ & 0,8961 \\
\hline \multicolumn{4}{|l|}{ Variável dependente: PES } \\
\hline$Y_{P E S}=-203957066+0,521765735 R C$ (Eq. 4) & 72,9109 & $0,00001^{*}$ & 0,8779 \\
\hline \multicolumn{4}{|c|}{ JOÃO PESSOA - PB } \\
\hline Variável dependente: DTP & Teste F & P-valor & $\mathrm{R}^{2}$ Ajustado \\
\hline$Y_{D T P}=-436097356+0,728132411 R C L$ (Eq. 5) & 47,9264 & $0,00006^{*}$ & 0,8243 \\
\hline \multicolumn{4}{|l|}{ Variável dependente: PES } \\
\hline$Y_{P E S}=-572518634+0,841558306 R C$ (Eq. 6) & 72,9513 & $0,00001^{*}$ & 0,8779 \\
\hline \multicolumn{4}{|c|}{ MACEIÓ - AL } \\
\hline Variável dependente: DTP & Teste F & P-valor & $\mathrm{R}^{2}$ Ajustado \\
\hline$Y_{\text {DTP }}=-436721802+0,734983076 R C L$ (Eq. 7) & 100,8733 & $0,00000 *$ & 0,9089 \\
\hline \multicolumn{4}{|l|}{ Variável dependente: PES } \\
\hline$Y_{P E S}=-709869878+0,907589857 R C$ (Eq. 8) & 68,5520 & $0,00001^{*}$ & 0,8710 \\
\hline \multicolumn{4}{|c|}{ NATAL - RN } \\
\hline Variável dependente: DTP & Teste $\mathrm{F}$ & P-valor & $\mathrm{R}^{2}$ Ajustado \\
\hline$Y_{D T P}=-225443710+0,638419273 R C L$ (Eq. 9) & 32,3223 & $0,00029 *$ & 0,7580 \\
\hline \multicolumn{4}{|l|}{ Variável dependente: PES } \\
\hline$Y_{P E S}=-150464919+0,58425846 R C$ (Eq. 10) & 18,5200 & $0,00198^{*}$ & 0,6366 \\
\hline \multicolumn{4}{|c|}{ RECIFE - PE } \\
\hline Variável dependente: DTP & Teste F & P-valor & $\mathrm{R}^{2}$ Ajustado \\
\hline$Y_{\text {DTP }}=-558989623+0,599574318 R C L$ (Eq. 11) & 60,7567 & $0,00002^{*}$ & 0,8566 \\
\hline \multicolumn{4}{|l|}{ Variável dependente: PES } \\
\hline$Y_{P E S}=-702125688+0,64227764 R C$ (Eq. 12) & 36,3372 & $0,00019 *$ & 0,7794 \\
\hline \multicolumn{4}{|c|}{ SALVADOR - BA } \\
\hline Variável dependente: DTP & Teste F & P-valor & $\mathrm{R}^{2}$ Ajustado \\
\hline$Y_{\text {DTP }}=-1336884429+0,687792003 R C L$ (Eq. 13) & 75,1242 & $0,00001^{*}$ & 0,8811 \\
\hline \multicolumn{4}{|l|}{ Variável dependente: PES } \\
\hline$Y_{P E S}=-1009140881+0,607402935 R C$ (Eq. 14) & 177,2945 & $0,00000^{*}$ & 0,9463 \\
\hline \multicolumn{4}{|c|}{ SÃo LUÍS - MA } \\
\hline Variável dependente: DTP & Teste F & P-valor & $\mathrm{R}^{2}$ Ajustado \\
\hline$Y_{D T P}=-599218815+0,774721415 R C L$ (Eq. 15) & 144,8842 & $0,00000^{*}$ & 0,9350 \\
\hline \multicolumn{4}{|l|}{ Variável dependente: PES } \\
\hline$Y_{P E S}=-434658564+0,660319187 R C$ (Eq. 16) & 23,6956 & $0,00088^{*}$ & 0,6941 \\
\hline \multicolumn{4}{|c|}{ TERESINA - PI } \\
\hline Variável dependente: DTP & Teste F & P-valor & $R^{2}$ Ajustado \\
\hline$Y_{\text {DTP }}=-332385866+0,652344318 R C L$ (Eq. 17) & 1004,7304 & $0,00000^{*}$ & 0,9901 \\
\hline \multicolumn{4}{|l|}{ Variável dependente: PES } \\
\hline$Y_{P E S}=-447206868+0,710685911 R C$ (Eq. 18) & 557,5808 & $0,00000 *$ & 0,9823 \\
\hline $\begin{array}{l}\text { Legenda: MQO = Mínimos Quadrados Ordináric } \\
\text { de } 5 \% \text {. }\end{array}$ & significância & s coeficier & tes ao nível \\
\hline
\end{tabular}


Nas equações pares (variável dependente PES), os coeficientes angulares estiveram na faixa de 0,5217 (Eq. 4) no município de Fortaleza a 0,9076 (Eq. 8) em Maceió. Isto indicou, no período de 2006 a 2016, que as despesas médias de pessoal e encargos sociais (PES) aumentaram cerca de $R \$ 0,52$ e $R \$ 0,91$ a cada aumento de $R \$ 1,00$ na receita corrente (RC). Os resultados sugerem uma diminuição de recursos para serem aplicados nos demais grupos de natureza de despesa (JED e ODC), o que pode inviabilizar a gestão pública para cumprir suas finalidades, haja vista que as despesas com pessoal são das atividades-meio das instituições públicas. Quando há sobra de receitas correntes para o pagamento de despesas correntes, as instituições podem investir em obras e instalações, ou seja, podem capitalizar ao invés de endividar (receitas de capital: empréstimos e financiamentos). Os aumentos de gastos da DTP, conforme observado na Tabela 2 ratificam a falta de gerenciamento dos recursos correntes para atender às demais despesas de custeio (JED e ODC).

Os resultados das equações de regressão da Tabela 3 permitem que sejam realizadas projeções das variáveis dependentes (DTP e PES), a partir de valores conhecidos ou de prováveis valores das arrecadações, desde que mantida as condições atuais (ceteris paribus). No caso do município de São Luís uma receita corrente líquida projetada (Eq. 15) de $R \$$ 2.800.000.000,00 (no ano de 2016 foi de $R \$ 2.438 .830 .286,59$ ) teria por consequência a possibilidade do gasto com pessoal (DTP/RCL) chegar em 56,07\%, o que ultrapassaria o limite permitido pela LRF.

Se a receita corrente projetada (Eq. 16) for de $\mathrm{R} \$ 3.000 .000 .000,00$ (em 2016 foi $\mathrm{R} \$$ 2.507.702.432,79), a relação PES/RC poderia chegar em 78,05\%, o que, por consequência, comprometeria os demais grupos de natureza das despesas correntes (JED e ODC). Convém lembrar, que existe uma margem de erro nas projeções de modelos regressivos (fatores residuais). Observa-se que as análises apresentadas em relação a Tabela 3 não foram abordadas nas pesquisas de Reis e Reis (2009); Araújo e Ribeiro (2013); Oliveira et al. (2013); Campagnoni, Platt Neto e Cruz (2014); Goulart et al. (2015) e Medeiros et al. (2017). As análises estatísticas representam também uma abordagem diferenciada desta investigação para compreender os gastos com pessoal. Os resultados, conforme preceitua a existência de conflitos de interesse e de assimetria informacional na Teoria da Agência aplicada ao setor público, poderão assim ser esclarecidos e diminuídos.

A Tabela 4 apresenta as variações percentuais das despesas com pessoal e a sua fonte de recursos. As análises representam outra forma de avaliar os gastos com pessoal. As pesquisas de Araújo e Ribeiro (2013) e de Campagnoni, Platt Neto e Cruz (2014) também realizaram essas análises.

Tabela 4 - Variação percentual de 2006 (ano base) para 2016 das despesas com pessoal (DTP e PES) e as receitas (RCL e RC)

\begin{tabular}{lcccc}
\hline Municípios & DTP & RCL & PES & RC \\
\hline Aracaju & $238,46 \%$ & $271,68 \%$ & $313,00 \%$ & $278,79 \%$ \\
Fortaleza & $236,91 \%$ & $188,28 \%$ & $197,41 \%$ & $183,57 \%$ \\
João Pessoa & $230,43 \%$ & $196,80 \%$ & $236,13 \%$ & $181,47 \%$ \\
Maceió & $252,21 \%$ & $188,34 \%$ & $272,96 \%$ & $197,90 \%$ \\
Natal & $201,01 \%$ & $154,36 \%$ & $192,79 \%$ & $143,45 \%$ \\
Recife & $209,54 \%$ & $141,35 \%$ & $221,64 \%$ & $139,99 \%$ \\
Salvador & $297,11 \%$ & $196,77 \%$ & $277,19 \%$ & $202,83 \%$ \\
São Luís & $262,68 \%$ & $186,01 \%$ & $338,37 \%$ & $185,51 \%$ \\
Teresina & $326,63 \%$ & $234,01 \%$ & $377,21 \%$ & $241,27 \%$ \\
\hline
\end{tabular}

Fonte: dados da pesquisa. 
A Tabela 4 foi elaborada para complementar as análises dos resultados apresentados na Tabela 2 (variações de percentuais aplicados a partir da razão entre a despesa e a fonte de recurso) e na Tabela 3 (variações de recursos a cada aumento de $\mathrm{R} \$ 1,00$ na fonte de recurso). Observa-se que a DTP aumentou mais no período de 2006 a 2016 em relação a sua fonte de recurso $(R C L)$ em todos os municípios analisados. Ocorreu de forma similar para as despesas do grupo de natureza de PES em relação a RC. As variações não são as mesmas, haja vista que as metodologias de cálculos são diferentes.

Os resultados apresentados na Tabela 4 evidenciaram que as despesas com pessoal aumentaram mais que as suas fontes de recursos. Isto representa uma preocupação com a gestão de pessoal. Os aumentos de despesas devem ocorrer dentro da variação de suas fontes para não comprometer a oferta de serviços públicos para a sociedade.

Os achados desta investigação são convalidados com a pesquisa de Araújo e Ribeiro (2013) que verificaram aumentos com a despesa de pessoal superior a arrecadação dos recursos em municípios da Região VIII do Zoneamento Sócio Econômico Ecológico (ZSEE), do Estado do Mato Grosso (MT).

Os resultados desta investigação divergem dos apresentados por Campagnoni, Platt Neto e Cruz (2014), que no caso da União a DTP cresceu 42,74\% entre 2000 e 2013 e a RCL cresceu $99,45 \%$ no mesmo período.

Verifica-se a partir dos resultados apresentados nas Tabelas 2 a 4, que a Teoria da Agência (MELLO, 2006; SUZART, 2012; SECCHI, 2013; MALMIR et al., 2014 e DAWSON et al., 2016) pode ser aplicada para esclarecer como os recursos disponibilizados pelos cidadãos (principais) estão sendo utilizados dentro das exigências legais e de forma comparativa entre os gestores públicos (agentes) das capitais nordestinas.

\section{CONSIDERAÇÕES FINAIS}

As entidades públicas necessitam de pessoal para o desempenho de suas atividades, uma vez que a elaboração delas requer ação de pessoas. Contudo, há uma limitação de gastos imposta, haja vista que os recursos (fontes) são escassos e as necessidades (oferta de bens e serviços para a sociedade) são enormes (saúde; educação; saneamento; segurança pública; defesa nacional; judiciária; previdência e assistência social; habitação etc.).

Neste sentido, o objetivo desta investigação é analisar a situação das despesas com pessoal das capitais nordestinas, no período de 2006 a 2016, em relação aos limites impostos pela Lei de Responsabilidade Fiscal (receita corrente líquida) e a receita corrente total. O descumprimento de determinação legal sobre os limites de gastos com pessoal significa desequilíbrio das contas públicas. A administração pública não poderá reajustar as remunerações dos servidores públicos, criar novos cargos, realizar novas admissões ou contratações de pessoal etc. A relação de gastos com pessoal, juros e encargos da dívida e outras despesas correntes e a receita corrente total significa a alocação de recursos para manter a entidade pública em funcionamento.

Discutir dados da execução orçamentária (receitas e despesas) é relevante para a sociedade como forma de exercer o controle (social). Estudos com base na Teoria da Agência aplicada ao setor público visam ampliar a discussão sobre o papel da sociedade (principal) e dos gestores públicos (agentes), além de diminuir a assimetria informacional sobre a gestão pública e de identificar os incentivos que levam o agente a servir melhor os interesses do principal. As despesas com pessoal representam um elemento-chave para uma gestão pública responsável. 
Observa-se que este estudo contribui para a sociedade (os cidadãos) tomar ciência da gestão pública no quesito de gastos com pessoal e suas fontes de recursos, além de contribuir para a literatura de análises/avaliações de resultados de ações governamentais com uma forma diferenciada na utilização de métrica quantitativa (análise de regressão) e assim pode motivar mais estudos correlatos com outras amostras (Estaduais e Municipais) ou da população (União e Distrito Federal). A estratégia da pesquisa de avaliação de resultados são meios para os cidadãos poderem exercer o controle social.

A contribuição deste estudo para a área de conhecimento da contabilidade aplicada ao setor público e das finanças públicas se refere a análise da alocação de recursos correntes totais com os gastos com pessoal, juros e encargos da dívida e outras despesas correntes para manter a entidade pública em funcionamento. O comprometimento excessivo de gastos com pessoal prejudica o funcionamento da entidade. Poderá faltar recursos para o pagamento das despesas de conservação dos bens móveis e imóveis e outras despesas de custeio.

Dever-se-ia discutir os gastos públicos correntes não somente relacionados com a receita corrente líquida e sim com todas as destinações dos recursos correntes. Os cidadãos pagam os impostos, taxas e contribuições e quando não há superávit corrente na execução, os recursos entregues para o Governo somente são utilizados em gastos de manutenção. Desse modo, para promover melhorias na qualidade de vida torna-se necessário realizar empréstimos e financiamentos (recursos de capital). Este procedimento significa endividamento, nos quais também são utilizados recursos dos contribuintes (pagamento de juros e encargos da dívida).

Outra forma de compreender o debate sobre gastos públicos e servir de reflexão pode ser resumida da seguinte forma: o Estado para atender as obrigações previstas na Constituição necessita obter os recursos (receitas públicas: correntes e de capital). Poderá criar o endividamento (empréstimos e financiamentos) para custear parte das despesas públicas (obras e investimentos). É necessário planejar e gerir os recursos, os quais devem ser realizados com o Orçamento Público.

Como limitação desta investigação, pode destacar o período curto da avaliação, além da confiabilidade dos dados disponibilizados para consulta e que os resultados são específicos para a amostra (não podem ser generalizados). Recomenda-se a realização de pesquisa similar para analisar outros municípios, bem como os Estados, o Distrito Federal e a União.

Finalizando, verificou-se que os municípios de Aracaju (ano de 2006), Natal (2012) e São Luís (2012 e 2015) descumpriram o limite máximo de gasto na relação DTP e RCL (gastos maiores que 54\%). Aracaju (2014), João Pessoa (2013 e 2015), Natal (2009, 2010, 2011, 2015 e 2016) e São Luís $(2013,2014$ e 2016) ultrapassaram o limite prudencial (gastos maiores que 51,30\%). Aracaju (ano de 2016), João Pessoa (2012 a 2016), Maceió (2013, 2014 e 2016), Natal (2015 e 2016), São Luís (2010 e 2016) comprometeram mais de 55\% (inclusive) dos recursos das receitas correntes (RC) em apenas um grupo de natureza de despesa (PES). No período de 2006 a 2016, um aumento de $\mathrm{R} \$ 1,00$ na RCL provocou, em média, um aumento (autorização para gastar) de cerca de $\mathrm{R} \$ 0,50$ a $\mathrm{R} \$ 0,77$ nas despesas total de pessoal (DTP). A DTP aumentou mais no período de 2006 a 2016 em relação a sua fonte de recurso (RCL) em todos os municípios analisados. O fato ocorreu de forma similar para as despesas do grupo de natureza de PES em relação a RC.

Conclui-se que os gastos com pessoal representam um dos componentes principais dos itens de despesas públicas correntes e que deveriam ser analisados em relação a receita 
corrente total, pois esta é utilizada também para cobrir os gastos com juros e encargos da dívida e outras despesas correntes. A despesa total de pessoal, nos municípios analisados, aumentou mais que as receitas correntes líquidas.

\section{REFERÊNCIAS}

ARAÚJO, J. J.; RIBEIRO, M. A. Despesas públicas: análise das despesas com pessoal nos municípios da região VIII do zoneamento sócio econômico ecológico - MT. Revista UNEMAT de Contabilidade, Volume 2, Número 3, Jan./Jun. 2013, p. 227-249.

ARROW, K. J. The Economics of Agency. Institute for Mathematical Studies in The Social Sciences, Stanford University, California, octuber 1984.

BASTOS, C. L.; KELLER, V. Aprendendo a aprender: introdução à metodologia científica. 17. ed. Petrópolis: Vozes, 2004.

BRASIL. Lei Complementar $n^{\circ}$ 101, de 04 de maio de 2000 (Lei de Responsabilidade Fiscal LRF). Estabelece normas de finanças públicas voltadas para a responsabilidade na gestão fiscal e dá outras providências. Diário Oficial [da] República Federativa do Brasil, Brasília, 05 de maio de 2000.

Lei no 4.320, de 17 de março de 1964. Estatui normas gerais de direito financeiro para elaboração e controle dos orçamentos e balanços da União, Estados, Municípios e do Distrito Federal. Diário Oficial [da] República Federativa do Brasil, Brasília, DF, 23 de março de 1964.

. Ministério do Planejamento, Orçamento e Gestão (MPOG). Portaria no 42, de 14 de abril de 1999. Atualiza a discriminação da despesa por funções de que tratam o inciso I do $\S$ 10 do art. $2^{\circ}$ e $\S 20$ do art. 8ㅇ, ambos da Lei $n$ ㅇ 4.320, de 17 de março de 1964, estabelece os conceitos de função, subfunção, programa, projeto, atividade, operações especiais, e dá outras providências. Diário Oficial [da] República Federativa do Brasil, Brasília, DF, 14 de abril de 1999.

Portaria Interministerial no 163, de 04 de maio de 2001. Secretaria do Tesouro Nacional (STN). Secretaria de Orçamento Federal (SOF). Dispõe sobre normas gerais de consolidação das Contas Públicas no âmbito da União, Estados, Distrito Federal e Municípios, e dá outras providências. Diário Oficial [da] República Federativa do Brasil, Brasília, DF, 07 de maio de 2001.

. Ministério do Planejamento, Orçamento e Gestão - MPOG. Instituto Brasileiro de Geografia e Estatística (IBGE). Cidades e Estados. Disponível em: <http://cidades.ibge.gov.br/xtras/home.php>. Acesso em: 20 jun 2017.

Ministério da Fazenda. Secretaria do Tesouro Nacional (STN). Sobre Prefeituras e Governos Estaduais. Disponível em: <https://www.tesouro.fazenda.gov.br/finbrafinancasmunicipais>. Acesso em: 10 jan. 2018. 
BRUNI, A. L. SPSS aplicado à pesquisa acadêmica. São Paulo: Atlas, 2009.

CAMPAGNONI, M.; PLATT NETO, O. A.; CRUZ, F. A observância dos limites para despesas com pessoal entre Poderes e órgãos da União no período de 2000 a 2013. Cadernos da Escola do Legislativo, Volume 16, Número 26, ago/dez 2014.

CÁLCULO EXATO. Atualização de um valor por um índice financeiro. Disponível em: < http://calculoexato.com.br/parprima.aspx?codMenu=FinanAtualizalndice $>$. Acesso em: 20 jan. 2018.

DAWSON, G. S.; DENFORD, J. S.; WILLIAMS, C. K.; PRESTON, D.; DESOUZA, K. C. An Examination of Effective IT Governance in the Public Sector Using the Legal View of Agency Theory. Journal of Management Information Systems, 2016, Vol. 33, N. 4, pp. 1180-1208.

FÁVERO, L. P. Análise de dados: modelos de regressão com Excel ${ }^{\circledR}$, Stata ${ }^{\circledR}$ e SPSS $^{\circledR}$. Rio de Janeiro: Elsevier, 2015.

GOULART, S. O.; ROSSATO, T. M.; LOPES, L. F. D.; ALMEIDA, D. M.; SAIDELLES, J.

Aplicabilidade da Lei de Responsabilidade Fiscal no controle de despesas com pessoal no CONDESUS da Quarta Colônia. Revista da UNIFEBE, v. 1, n. 16, 2015. p. 20-34.

JENSEN, M. C.; MECKLING, W. H. Theory of the Firm: Managerial Behavior, Agency Costs and Ownership Structure. Journal of Financial Economics, Harvard, v. 3, n. 4, p. 305-360, out. 1976.

JULNES, P. L. Performance measurement: An effective tool for government accountability? The Debate Goes On, 12 (2), 2006, p. 219-235.

LATTIN, J.; CARROLL, J. D.; GREEN, P. E. Análise de dados multivariados. Tradução de Harue Avritscher. São Paulo: Cengage Learning, 2011. 456p.

LERUTH; L.; PAUL, E. A principal-agent theory approach to public expenditure management systems in developing countries. IMF Working Paper, 06/204, September 2006, p. 1-43.

MACHADO, M. R.; MACHADO, M. A. V.; HOLANDA, F. M. A Indicadores de desempenho utilizados pelo setor hoteleiro da cidade de João Pessoa/PB: um estudo sob a ótica do Balanced Scorecard. Turismo - Visão e Ação, vol. 9, n.3 p. 393-406, set./dez. 2007.

MALMIR, A.; SHIRVANI A.; RASHIDPOUR, A.; SOLTANI, I. Citizen relationship management and principal/agent theory. International Journal of Managing Value and Supply Chains (IJMVSC), Vol. 5, N. 3, P. 83-90, September 2014. DOI: 10.5121/ijmvsc.2014.5307.

MARTINS, G. A.; THEÓPHILO, C. R. Metodologia da investigação científica para ciências sociais aplicadas. 2. ed. São Paulo: Atlas, 2009.

MATIAS-PEREIRA, Manual de metodologia da pesquisa Científica. 3. ed. São Paulo: Atlas, 2012. 
MEDEIROS, K. R.; ALBUQUERQUE, P. C.; TAVARES, R. A. W.; SOUZA, W. V. Lei de Responsabilidade Fiscal e as despesas com pessoal da saúde: uma análise da condição dos municípios brasileiros no período de 2004 a 2009. Ciência \& Saúde Coletiva, 22(6):17591769, 2017.

MELLO, G. R. Governança corporativa no setor público federal brasileiro. 2006. $127 \mathrm{f}$. Dissertação (Mestrado em Ciências Contábeis). Faculdade de Economia, Administração e Contabilidade da Universidade de São Paulo, São Paulo. 2006.

MONSMA, K. Repensando a escolha racional e a teoria da agência: fazendeiros de gado e capatazes no século XIX. Rev. bras. Ci. Soc., São Paulo, v. 15, n. 43, p. 83-114, 2000.

OLIVEIRA, F. P. S.; ARAÚJO, R. M.; ANEZ, M. E. M.; CARDENAS, L. Q.; ROCHA, L. A. Análise em painel do comportamento das despesas totais com pessoal dos municípios da Região Metropolitana de Natal. Revista UNIABEU, Belford Roxo, v. 6, número 12, janeiro- abril, 2013, p. 128-150.

REIS, C. A.; REIS, K. S. P. Análise do comportamento das despesas com pessoal do Estado de Rondônia com o advento da Lei de Responsabilidade Fiscal. Saber Científico, Porto Velho, 2 (1): 15 - 27, jan./jun., 2009.

ROCHA, I.; PEREIRA, A. M.; BEZERRA, F. A.; NASCIMENTO, S. do Análise da produção científica sobre teoria da agência e assimetria da informação. REGE-Revista de Gestão, v. 19, n. 2, p. 329-341, 2012.

SECCHI, L. Políticas públicas: conceitos, esquemas de análise, casos práticos. 2. Ed. São Paulo: Cengage Learning, 2013.

SILVA, M. C.; NETO, A. F. S.; FIRMINO, J. E.; SILVA, J. D. G. Avaliação de efetividade de funções sociais de governo nas capitais estaduais. Boletim Governet de Administração Pública e Gestão Municipal, volume único, n. 58, p. 984-1000, julho 2016.

SUZART, J. A. S. As Instituições Superiores de Auditoria: um estudo do nível de transparência fiscal dos países. Contabilidade, Gestão e Governança - Brasília, v. 15, n. 3, p. 107-118, set./dez. 2012.

TEIXEIRA, H. J.; SANTANA, S. M. Remodelando a gestão pública. São Paulo: Edgar Blucher, 1994. 